\title{
Fish sounds and boat noise are prominent soundscape contributors in an urban European estuary
}

\author{
Manuel Vieira $^{\text {a,b, }}$, Paulo J. Fonseca ${ }^{\text {a }}$, M. Clara P. Amorim ${ }^{\mathrm{b}, 1}$ \\ ${ }^{\text {a }}$ Departamento de Biologia Animal and cE3c - Centre for Ecology, Evolution and Environmental Changes, Faculdade de Ciências, Universidade de Lisboa, Lisbon, \\ Portugal \\ ${ }^{\mathrm{b}}$ MARE_Marine and Environmental Sciences Centre, ISPA, Instituto Universitário, Lisbon, Portugal
}

\section{A R T I C L E I N F O}

\section{Keywords:}

Soundscape ecology

Underwater noise

MSFD

Estuarine soundscape

Meagre

Lusitanian toadfish

\begin{abstract}
A B S T R A C T
Passive acoustic monitoring is a valuable tool for non-intrusive monitoring of marine environments, also allowing the assessment of underwater noise that can negatively affect marine organisms. Here we provide for the first time, an assessment of noise levels and temporal soundscape patterns for a European estuary. We used several eco-acoustics methodologies to characterize the data collected over six weeks within May 2016 - July 2017 from Tagus estuary. Biophony was the major contributor dominated by fish vocalizations and the main driver for seasonal patterns. Maritime traffic was the major source of anthropogenic noise, with daily patterns monitored using $1584 \mathrm{~Hz}$ third-octave band level. This indicator avoided biophony and geophony, unlike other indicators proposed for the EU Marine Strategy Framework Directive. Furthermore, the frequency overlap between anthropophony and biophony demands precautionary actions and calls for further research. This study provides an assessment that will be useful for future monitoring and management strategies.
\end{abstract}

\section{Introduction}

Soundscape analysis has the potential to be a powerful tool for management and conservation efforts (Towsey et al., 2014; Sueur and Farina, 2015; Krause and Farina, 2016; Farina and Gage, 2017; Pavan, 2017; Farina, 2019). Supported by recent advances in passive acoustic monitoring (PAM), this non-invasive tool allows the evaluation of biodiversity, species density, habitat use, activity patterns and the impacts of human activities on marine organisms (Farina and Gage, 2017; Sueur et al., 2008; Obrist et al., 2010; Marques et al., 2013).

Anthropophony (man-made noise), Biophony (sounds from biological activity including vocalizations) and Geophony (sounds generated by geophysical and meteorological events) are the major components of a soundscape (Pijanowski et al., 2011). These components characterize each environment and can be particularly important for marine organisms (Montgomery and Radford, 2017; de Jong et al., 2020). Indeed, many marine organisms including cetaceans, fish and invertebrates use sounds to interpret their surroundings and/or to communicate (Kaatz, 2002; Cato et al., 2005; Remage-Healey et al., 2006; Vermeij et al., 2010; Chapuis and Bshary, 2010). For some, acoustic communication can be crucial for reproductive success (e.g. Amorim et al., 2016; Nabi et al., 2018). The major relevance of sound in marine environments is probably related to its velocity (travels five times faster in water than in air) and ability to propagate long distances (Mann and Lobel, 1997; Popper and Hawkins, 2009; Buscaino et al., 2011). However, man-made underwater noise has increased in the last decades and is now acknowledged as a chronic source of pollution that is changing underwater soundscapes and imposing new constraints on animals, including in their ability to communicate acoustically (Marine Strategy Framework Directive - MSFD, European Commission, 2008; Normandeau Associates, Inc, 2012). Anthrophonic noise can cause a wide range of effects, such as behavioural avoidance, temporary threshold shifts, or even death (Popper and Hastings, 2009). In this context, it is urgent to assess marine soundscapes, especially coastal and transitional areas (e.g. estuaries) in which high-density anthropogenic sound sources coexist with marine fauna.

Soundscapes change through space and time. Several articles have characterized aspects of the soundscape in underwater habitats. Most traditional approaches used short-term measurements at one or several locations or habitats (e.g. Radford et al., 2010; McWilliam and Hawkins,

\footnotetext{
* Corresponding author at: Departamento de Biologia Animal and cE3c - Centre for Ecology, Evolution and Environmental Changes, Faculdade de Ciências, Universidade de Lisboa, Lisbon, Portugal.

E-mail address: manuel_1990_v@hotmail.com (M. Vieira).

1 Present address: Departamento de Biologia Animal, Faculdade de Ciências, Universidade de Lisboa, Lisbon, Portugal.
} 
2013; Lillis et al., 2014). Recent technological advances and the greater affordability of acoustic equipment, however, currently allow the use of long-term recordings (e.g. Putland et al., 2017) encompassing days, months or even years. These enhanced recording capabilities have been accompanied by the development of powerful analytic methodologies (e.g. ecoacoustics indices, several long-term visualization techniques, and automatic detection and classification algorithms). Several studies focusing on ambient and anthropogenic noise (e.g. Merchant et al., 2014; Romagosa et al., 2017; Soares et al., 2020), mostly applied visual methods conjugated with the measurement of broadband and one-third octave band levels (SPL and TOL). In particular, the European MSFD suggested the use of $63 \mathrm{~Hz}$ and $125 \mathrm{~Hz}$ TOL to quantify anthropogenic noise, although several authors also recommended the assessment of sound frequencies up to $500 \mathrm{~Hz}$ in shallow waters (Merchant et al., 2014; Picciulin et al., 2016). On the other hand, studies focusing on the presence of vocal species and temporal patterns of acoustic activity typically used visual inspection of recordings to pinpoint animals vocalizations (e.g. Amorim et al., 2006; Luczkovich et al., 2008; Carriço et al., 2020a,b), or more recently used automatic recognition detection and classification approaches, such as simple energy thresholds and matched filter or unsupervised methods using machine learning like Gaussian mixture models (GMMs), artificial neural networks (ANN) and hidden Markov models (HMMs) (e.g. Monczak et al., 2019; Vieira et al., 2021). Lastly, some studies attempted to present an overview considering several aspects of a soundscape like biophony and anthropophony (e.g. Staaterman et al., 2014; Marley et al., 2016; Putland et al., 2017).

The Tagus estuary is one of the largest in Europe with an area of about $320 \mathrm{~km}^{2}$, and its ecological and economic values are well recognized. The western area of the estuary is densely urbanized by the city of Lisbon and its metropolitan area, contrasting with its eastern upstream area that is legally protected as a natural reserve (Tavares et al., 2015) and classified as a Site of Community Importance (PTCONO009) and a Special Protection Area (PTZPE0010) under the European NATURA 2000 network (Directive 92/43/EEC; Directive 2009/147/EC; Fig. 1). This estuary is characterized by a high number of fish species and acts as a nursery area for several species (Costa and Bruxelas, 1989, Costa and Cabral, 1999; Table S1). More than fifty fish species have been reported in Tagus estuary (e.g. Cabral et al., 2001; Morais et al., 2017) including several soniferous species (Table S1). Moreover, according to Cabral et al. (2001) since the 1970s there have been some changes on the fish communities with an increase of more meridional highly vocal species such as the Lusitanian toadfish (Halobatrachus didactylus; Amorim et al., 2006) and the meagre (Argyrosomus regius; Lagardère and Mariani, 2006). These changes may be associated with global warming (Santos et al., 2002; Thiel et al., 2003), although the observed reduction in pollution levels could also be responsible for several changes (Cabral et al., 2001; Rodrigues et al., 2020). Concurrently, an increase in boat traffic has occurred (Ștefănescu et al., 2013). Nowadays, cargo and passenger ships dominate the traffic in the Tagus estuary as reported by the Automatic Identification System (AIS, i.e. a tracking system that uses transceivers on ships and large boats to report their geographical positions), with some routes being dominated by the ferryboats that connect Lisbon to Montijo, Cacilhas, Seixal and Barreiro (Rong et al., 2015). There are also several smaller boats (Vieira et al., 2020), however, the number and routes followed are not well known since they are not required to carry an AIS (Imo, 2001).

Here, we provide a first overview of the Tagus estuary soundscape. Using recordings from six weeks distributed over a year in a single location, the aims were to (1) describe the major contributors to the underwater soundscape; (2) provide a first assessment of noise levels; and (3) characterize major daily and seasonal patterns.

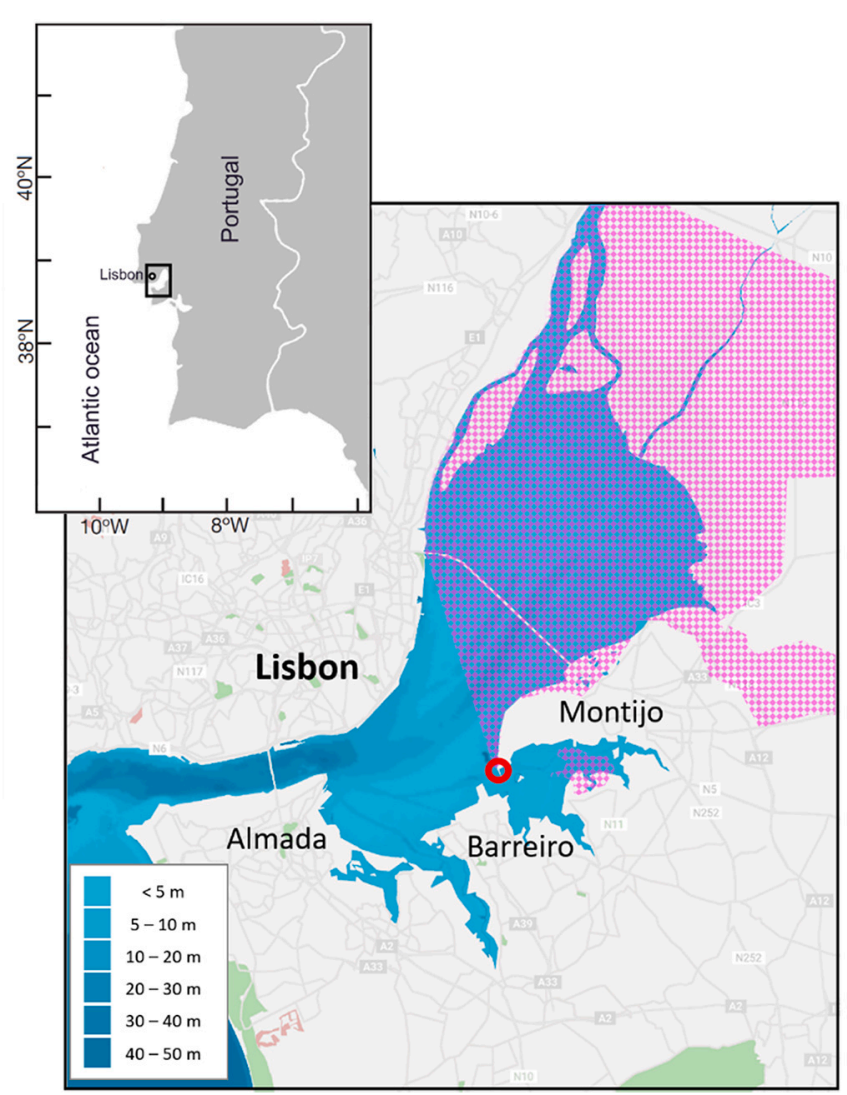

Fig. 1. Location of the underwater recording site (red dot) in the Tagus estuary. The areas classified as a Site of Community Importance (PTCON0009) and a Special Protection Area (PTZPE0010) under the NATURA 2000 network are represented in pink. Bathymetry data adapted from the Hydrographic Institute. (For interpretation of the references to colour in this figure legend, the reader is referred to the web version of this article.)

\section{Materials and methods}

\subsection{Acoustic recordings and meteorological data}

Recording equipment was deployed in a pier with restricted access in the Portuguese Air Force base no. 6 (BA6, Montijo, Portugal; $38^{\circ} 42^{\prime} \mathrm{N}$, $8^{\circ} 58^{\prime} \mathrm{W}$; Fig. 1). This location is situated at the southern bank of the estuary and on the south-west boundary of the protected areas under the European NATURA 2000 network. It is also, near one of the major routes of passenger's ferryboats (Rong et al., 2015), and is a place where small open deck fishing boats are observed daily (Vieira et al., 2020). The presence of meagre (A. regius) and Lusitanian toadfish (H. didactylus) has previously been observed on this site (Vieira et al., 2020; Vieira et al., 2021).

Underwater recordings were obtained between May 2016 and July 2017, using a High Tech 94 SSQ hydrophone (High Tech Inc., Gulfport, MS, USA; sensitivity of $-165 \mathrm{~dB}$ re. $1 \mathrm{~V} / \mu \mathrm{Pa}$, frequency response up to 6 $\mathrm{kHz}$ within $\pm 1 \mathrm{~dB}$ ) anchored at about $20 \mathrm{~cm}$ from the bottom. To minimise current-induced hydrodynamic noise the hydrophone was attached to a stainless-steel holder projecting from a concrete base. The signal from the hydrophone was recorded continuously by a 16 channel stand-alone data logger (Measurement Computing Corporation LGR5325, Norton, Virginia, USA, 16 bits resolution; sampling rate of 22 $\mathrm{kHz}$ on 2016 and $4 \mathrm{kHz}$ on 2017). Recordings from 2016 were downsampled from $22 \mathrm{kHz}$ to $4 \mathrm{kHz}$. Depth at hydrophone location ranged from ca. 2 to $6 \mathrm{~m}$ depending on tide level.

Air temperature and wind speed were recorded by a weather station located at BA6. These data were sampled every $5 \mathrm{~min}$. Tide level from 
May 2016 to January 2017 was provided by Hydrographic Institute (Lisbon, Portugal; $38^{\circ} 42^{\prime} \mathrm{N}, 9^{\circ} 07^{\prime} \mathrm{W}$ ).

\subsection{Soundscape analysis}

All acoustic data were analysed using $\mathrm{R}$ software ( $\mathrm{R}$ Core Team, 2018).

We considered recordings made during six different weeks distributed within the period May 2016 - July 2017 (May, July and November 2016, and January, April and July 2017). This selection should capture an overview of the seasonal variation in the soundscape.

To investigate the sound level variation over the duration of recordings the following quantitative measures were computed: averaged broadband sound pressure level (SPL, 20-2000 Hz); and averaged sound level in third-octave bands (TOL). Spectral Probability Density plots (SPD), Long-Term Spectral Average plots (LTSA) and Cumulative Distribution Function of SPL (CDF) were also computed for each week to examine variations of the energy distribution along frequency. All these features were computed and calibrated adapting the code available by Merchant et al. (2015) (SPL, TOL, LTSA and CDF: FFT 1024, Hann window, 50\% overlap, averaged for each minute; $1 \mathrm{~s}$ averaged PSDs were used to create the SPD). The correction factor for calibration was calculated using the hydrophone sensitivity, system gain and zero-topeak voltage of the analog-to-digital converter. Recordings were also inspected both aurally and visually using Adobe Audition 3.0 software (Adobe Systems, San José, CA, USA) to identify the sound types corresponding to the geophony, biophony and anthropophony soundscape components. Note that this inspection was performed on the non-downsampled recordings.

TOLs pairwise correlations were performed considering 1-minute averages.

Sound level differences between the different selected weeks were evaluated using non-parametric one-way ANOVAs (Krustal-Wallis test), considering 1-hour arithmetic averages. This test was selected since homogeneity of variances and normality were not met. Post-hoc Dunn tests were used for pairwise comparisons.

To evaluate the relation between soundscape and abiotic factors, Generalized Additive Models (GAM) with a gamma distribution were used. GAM is a non-parametric, regression technique not restricted by linear relationships, and it is flexible regarding the statistical distribution of the data (Hastie and Tibshirani, 1990; Wood, 2017). The effect of the explanatory variables wind speed, tide level and tidal vertical velocity were assessed using data from May 2016 to January 2017, considering 1-hour arithmetic averages. Tidal vertical velocity is the time derivative of tidal water levels. Furthermore, the effect of time of day was also assessed. GAMs were chosen because preliminary analysis of the time-series indicated non-linear relationships (Hastie and Tibshirani, 1990; Wood, 2017). Thin plate regression splines were used, and all terms were subject to the second-order penalty. Parameters were estimated using restricted maximum likelihood (REML). The interactions of the covariates were taken into account with tensor product interactions (Wood, 2006). These interaction terms were only retained when they were significantly different from a zero (flat) function. This statistical analysis was conducted in $\mathrm{R}$ using the 'gam' function from 'mgcv' library. Model fit was evaluated through visual inspection of residual plots and diagnostic information produced using the'gam.check' function (Wood, 2001).

\section{Results}

\subsection{Soundscape sources}

Fish sounds were responsible for major seasonal and daily changes in the soundscapes. Anthropogenic noise associated with boating repeatedly appeared throughout the day and overlapped the frequency band used by the fish. Daily tidal rhythms were also produced an abundancy of sounds. A set of one week long-term averaged spectrograms is shown in Fig. 2, representing Autumn (November 2016), Winter (January 2017), Spring (April 2017) and Summer (July 2017).

\subsubsection{Biophony}

Only fish calls from meagre and Lusitanian toadfish were recognized. Lusitanian toadfish sounds include boatwhistles, double-croaks and grunt trains (sound type names as reported by Amorim et al., 2008). Boatwhistles were usually observed in bouts and in higher number (Fig. 2c). These calls occurred in all datasets (May, July and November 2016, and January, April and July 2017). Peak activity was observed in July 2017, with a noticeable pattern of the ca. $110 \mathrm{~Hz}$ and $220 \mathrm{~Hz}$ boatwhistles' harmonics in the long-term averaged spectrogram (Fig. 2a,c, highlighted by the 2 yellow arrows). The week sampled in July 2016 also presented hours with noticeable presence of boatwhistles, but much less than July 2017. In November 2016 and January 2017, the presence of Lusitanian toadfish calls was sporadic.

Meagre produced massive choruses at dusk in May 2016 and April 2017 (see Fig. 2a,b, highlighted by the blue arrow). July 2016 also presented choruses on some days but with shorter duration. In these choruses the most common calls observed were the intermediate grunts (sounds with 7- 29 pulses) and long grunts (more than 30 pulses; sound type nomenclature as reported in Vieira et al., 2019). Fig. 2b represents the choruses dominated by long grunts with high rate of overlap, forming a mostly continuous roar. Note that 1-3 pulsed calls were also observed, usually produced in a bout. In November 2016 and January 2017 meagre calls were also detected (Figs. S3 and S4). In the colder months, only short grunts were detected.

\subsubsection{Anthropophony}

The most abundant anthropogenic noise was produced by boats. In this location it is common to observe small boats (mostly open deck fishing boats with outboard engine) and ferryboats that transport passengers between Lisbon and Montijo (examples in Fig. 3a and b). Most boat passages occurred from ca. 5 am to $23 \mathrm{pm}$. Noise from small boats and ferryboats passing-by usually presented Lloyd's mirror effect (Fig. 3a) and occupied a wide frequency range from ca. $20 \mathrm{~Hz}$ up to the Nyquist limit of our recordings. The Lloyd's mirror effect is the result of the interactions of out-of-phase reflections of the sound in the recording position and shows a shift on the frequencies observed according to the distance of a moving source, usually presenting a symmetrical spectrogram between approach and departure from the recording device (Carey, 2009). Some small boats also produced noise restricted to low frequencies $(<200 \mathrm{~Hz}$; example in Fig. 3b). At this site, it was also possible to detect some airplanes landing or taking off from the air force base (Fig. 3c; sound type confirmed with simultaneous visual observation in the recording site) as well as several other anthropogenic sounds from unknown sources.

\subsubsection{Geophony}

Tidal currents and wind generated noise on the several datasets. Ebb and flood tide produced low frequency sounds (e.g. Fig. 3d). Tidal flow also increased hydrophone self-mooring sounds and or knock sounds produced by the impact of objects flowing within the water current (Fig. 3e). The latter can occur across the recorded spectrum, but most energy was concentrated at low frequencies. Low frequency short span waves breaking sounds occurred throughout the dataset (e.g. Fig. 3f). We could identify two sources of wave breaking sounds: increased wind speed and boat passages (see end of boat noise in Fig. 3a).

\subsection{Sound level patterns}

Averaged broadband SPL (20-2000 Hz) was highly correlated with averaged sound level in $39 \mathrm{~Hz}$ to $630 \mathrm{~Hz}$ third-octave bands (TOL) (Fig. S7; $r>0.6$ ). Furthermore, pairwise correlation between TOLs presented high correlation $(r>0.4)$ in 4 groups: (1) very low frequencies 


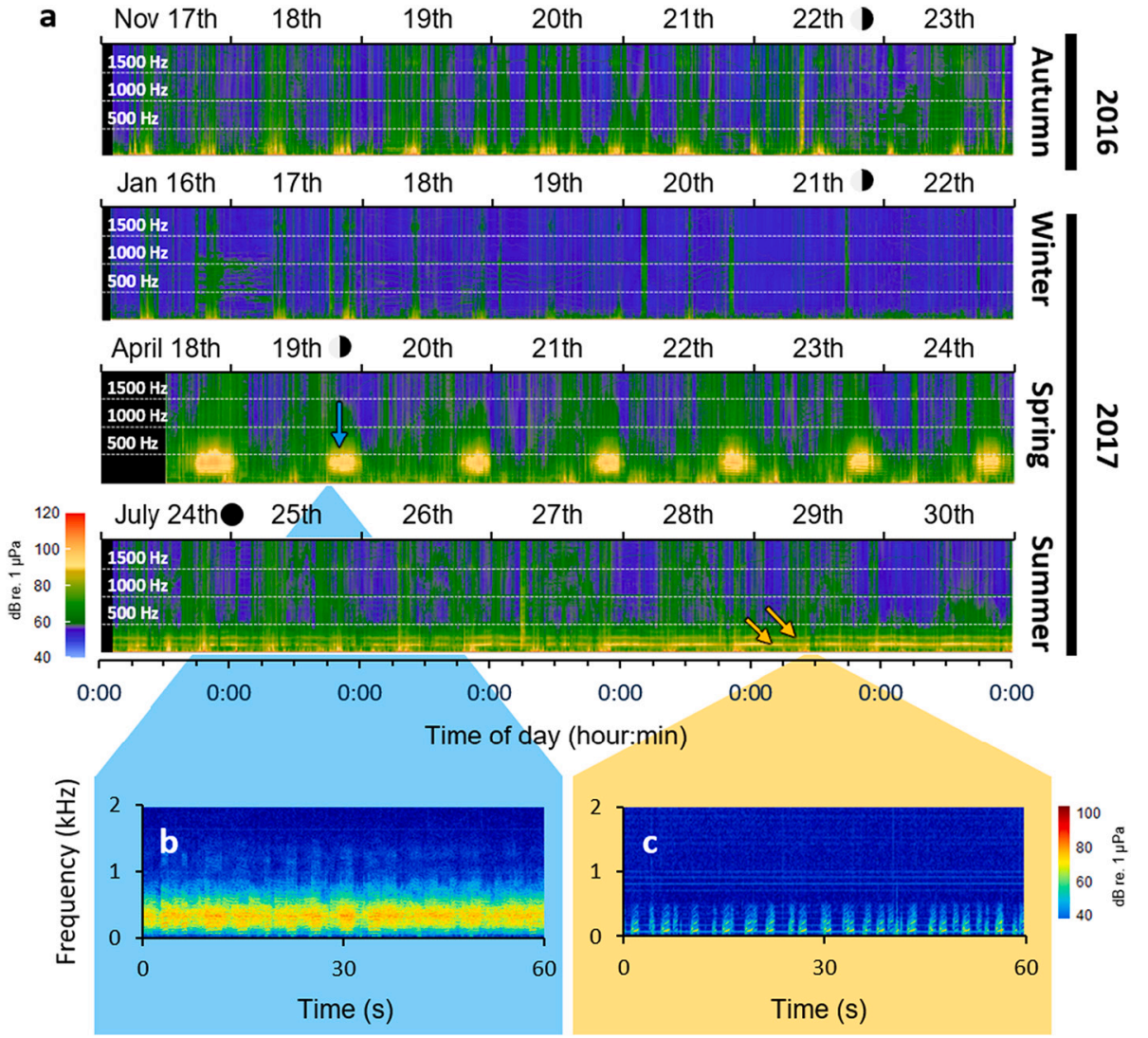

Fig. 2. Long-term spectrograms from Tagus estuary representing the several seasons from November 2016 to July 2017. (b,c) depicts in detail the detected fish sounds: (b) depicts a 1-min spectrogram from April 2017 with a meagre chorus dominated by long grunts with high rate of overlap, forming a mostly continuous roar; and (c) depicts a 1-min spectrogram with a bout of Lusitanian toadfish boatwhistles detected in July 2017. Arrows highlight examples of the presence of meagre (blue) and the presence of $110 \mathrm{~Hz}$ and $220 \mathrm{~Hz}$ boatwhistles' harmonics visible during Lusitanian toadfish chorus (yellow). Long term averaged spectrogram settings: sampling frequency: $4 \mathrm{kHz}$, FFT size: 1024, window type: Hann, $50 \%$ overlap, averaged for 1-minute segments. Spectrogram settings used a FFT size of 512. (For interpretation of the references to colour in this figure legend, the reader is referred to the web version of this article.)
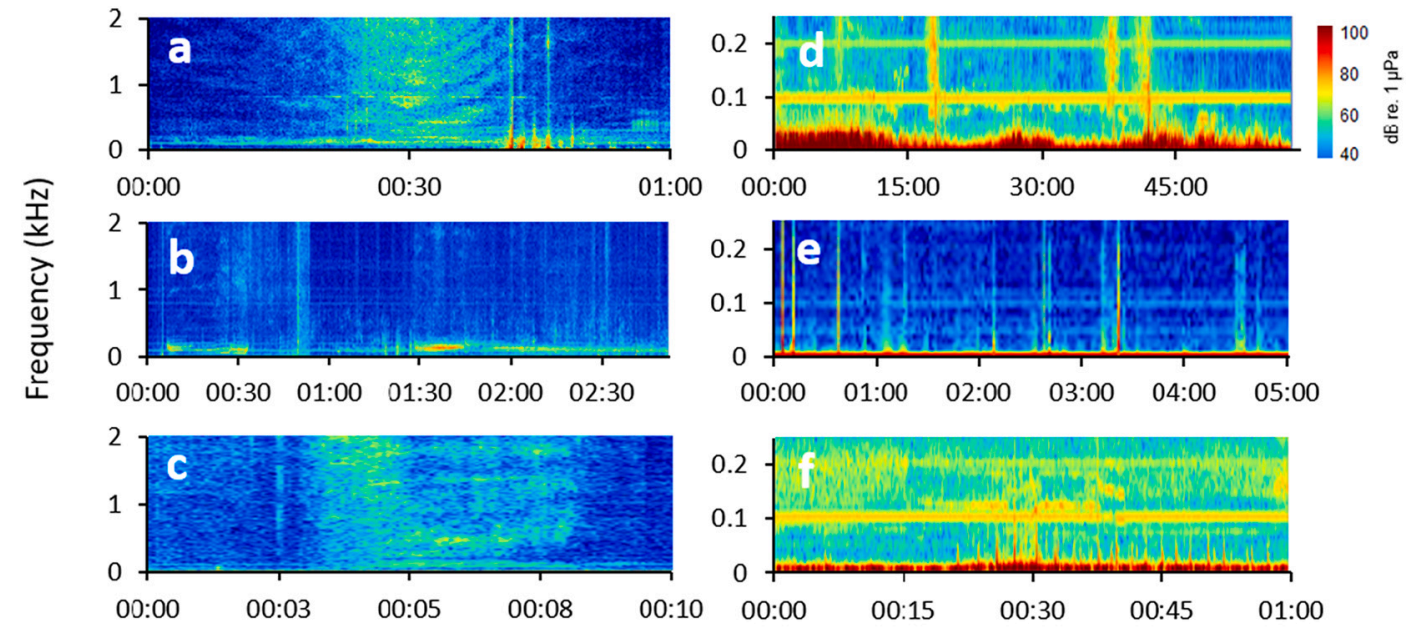

Time (min:s)

Fig. 3. Spectrograms of anthropogenic and geophonic sounds: (a) ferryboat in April 2017; (b) small boat manoeuvring in April 2017; (c) airplane of the air force detected in April 2017; (d) 1 h-spectrogram with low frequency tidal influence noise in May 2016 (see red area); (e) flow noise in January 2017 observed as broadband short noise (green and red vertical lines); and (f) consecutive breaking surf wave sounds in May 2016. Note a $50 \mathrm{~Hz}$ electrical noise (and respective harmonics) from the recording setup is also noticeable in panels (d-f). (For interpretation of the references to colour in this figure legend, the reader is referred to the web version of this article.)

under $35 \mathrm{~Hz}$; (2) frequencies between 35 and $140 \mathrm{~Hz}$; (3) frequencies between 140 and $891 \mathrm{~Hz}$; and frequencies higher than $891 \mathrm{~Hz}$. Only TOLs with centre frequency of $63,125,500$ and $1584 \mathrm{~Hz}$ were selected for further analysis. Very low frequencies were excluded. The 63 and $125 \mathrm{~Hz}$ centred TOLs were selected because they are recommended by the MSFD of the European Union to monitor low-frequency anthropogenic noise. The $500 \mathrm{~Hz}$ TOL was selected taking also into account that several authors recommended the use of such frequencies in shallow waters (Merchant et al., 2014; Picciulin et al., 2016). Lastly, the $1584 \mathrm{~Hz}$ TOL was selected to represent the group of highest recorded frequencies (Fig. S7). Descriptive statistics for SPL, 1548, 500. 125 and $63 \mathrm{~Hz}$ TOL, atmospheric temperature, wind speed and tide level are presented in Table S2. 


\subsubsection{Wind and tidal influence}

Sound level was affected by the tide and wind speed. Tide level and tidal vertical velocity affected non-linearly the sound levels at every band except TOL $1584 \mathrm{~Hz}$ (see Fig. 4; Table 1). GAM's also indicate an increase of sound level at lower frequencies during high tide $(p<0.001)$. On the TOL $63 \mathrm{~Hz}$ and SPL the increase was especially high at the ebb tide ( $p<0.001$; cf. tidal velocity in Fig. 4). SPLs increase at ebb-current was ca. $20 \mathrm{~dB}$ greater than in the stand of the tide (when tidal velocity is zero). Wind speed proportionally increased sound level at all analysed bandwidths $(p<0.001)$, although the increase in sound level was higher at the $63 \mathrm{~Hz}$ TOL.

\subsubsection{Daily temporal patterns}

Daily patterns of noise levels were driven by meagre choruses and boat passages. Meagre chorus raised SPL and $500 \mathrm{~Hz}$ TOL at dusk (Fig. 2a,b; cf. Figs. S1, S2 and S5). This can be observed in the GAM as a non-linear relation of those sound level metrics with time of day increasing since $15 \mathrm{~h}$ and peaking at ca. 20-23 h (Fig. 4 and Table $1 ; p<$ 0.001). Lower frequency TOLs (63 and $125 \mathrm{~Hz}$ ) showed a non-linear correlation, with lower levels during the day (Fig. 4; $p<0.001$ ). This can be also be partially observed in the SPL. Using SPL and 500, 125 and $63 \mathrm{~Hz}$ TOLs, the marked daily pattern of marine traffic at this site could not be observed. However, boat noise incidence could be monitored using 1-min averaged $1584 \mathrm{~Hz}$ TOL (cf. Figs. S1-6). Anthropogenic noise produced by boats passing-by increased the $1584 \mathrm{~Hz}$ TOL from ca. 5 am to $11 \mathrm{pm}$ (Figs. S1-6). This can be observed on the GAM also presenting a non-linear correlation with time of day (Fig. 4; $p<0.001$ ). A peak at ca. 8 am and a smaller peak at ca. $6 \mathrm{pm}$ can also be observed and are concurrent with the rush hour periods when more ferryboat passages occur. Furthermore, Sundays presented lower incidence of boat passages (see May 8th, Nov 20th and July 30th in Figs. S1, S3 and S6).

\subsubsection{Seasonal temporal patterns}

Some clear differences were observed throughout the sampled days representing spring, summer and autumn/winter. There was a significant difference in broadband SPL $(20-2000 \mathrm{~Hz})$ according to month (Krustal-Wallis test, $\chi^{2}{ }_{(5)}=387.2, p<0.001$; Fig. 5). During January, the broadband SPL was lower $(90.5 \pm 5.4 \mathrm{~dB}$ re. $1 \mu \mathrm{Pa}$; mean $\pm \mathrm{SD}$; Dunn test, $p<0.001$ ) than the other months. November was the second-to-last $(95.2 \pm 6.6 ; p<0.001)$ in broadband SPL. The highest SPL were

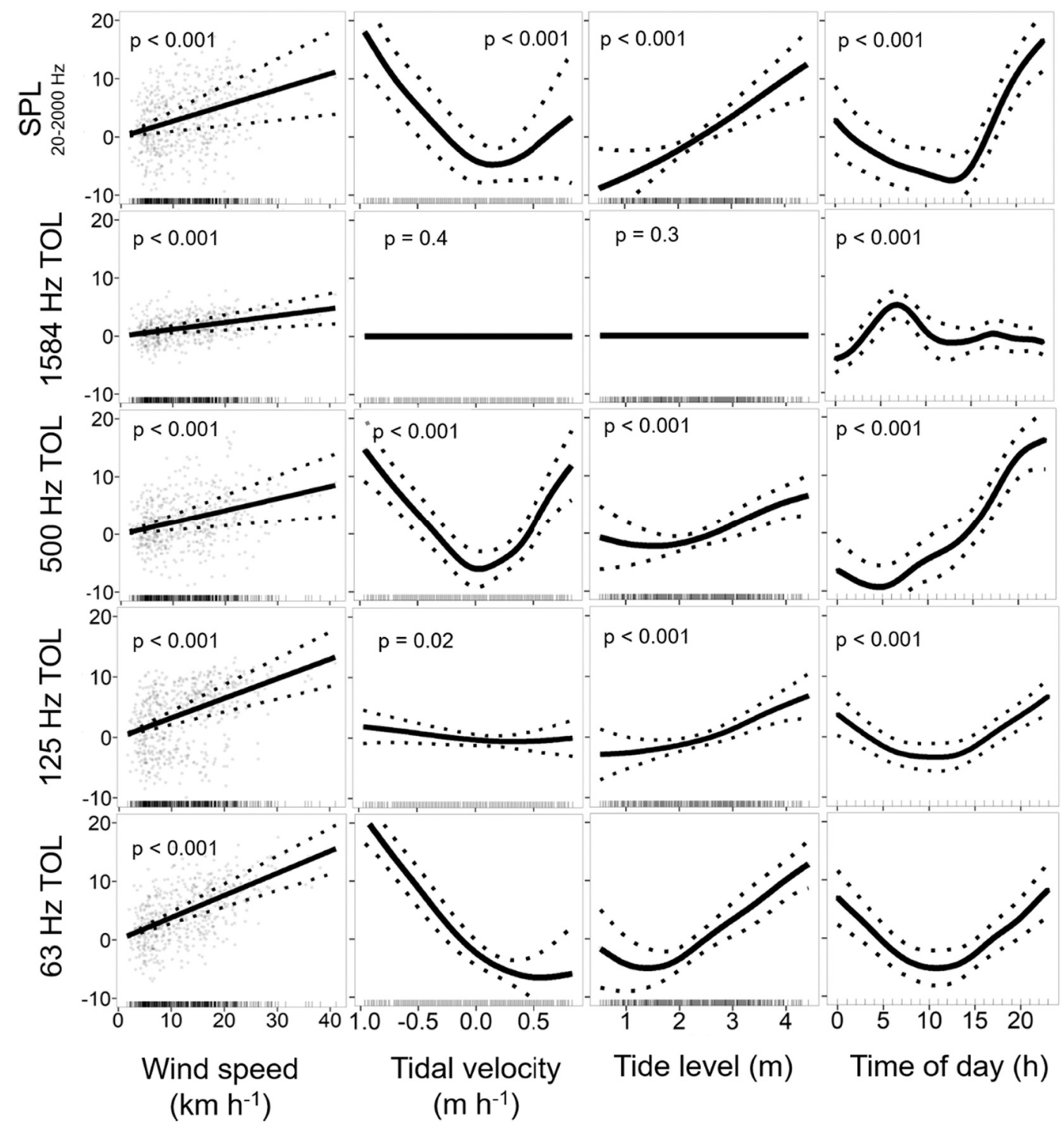

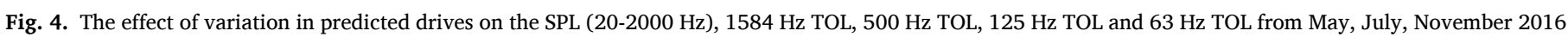

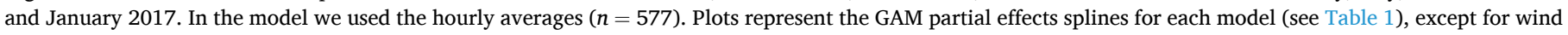
that was assumed as linear. Functions are presented as solid lines, dashed lines denote confidence interval, and dots indicate the partial residuals. 
Table 1

Results of generalized additive models (GAM) assessing the parameters that explain the daily patterns of SPL and TOLs.

\begin{tabular}{|c|c|c|c|c|c|c|c|c|c|c|}
\hline & \multicolumn{2}{|l|}{ SPL } & \multicolumn{2}{|c|}{$1584 \mathrm{~Hz}$ TOL } & \multicolumn{2}{|c|}{$500 \mathrm{~Hz}$ TOL } & \multicolumn{2}{|c|}{$125 \mathrm{~Hz}$ TOL } & \multicolumn{2}{|c|}{$63 \mathrm{~Hz}$ TOL } \\
\hline $\mathrm{n}$ & 577 & & 577 & & 577 & & 577 & & 577 & \\
\hline$r^{2}$ & 0.70 & & 0.48 & & 0.68 & & 0.50 & & 0.70 & \\
\hline Deviance explained & $72.6 \%$ & & $51.7 \%$ & & $71.4 \%$ & & $53.4 \%$ & & $72.6 \%$ & \\
\hline Linear predictor & EDF & $p$-value & EDF & p-value & EDF & p-value & EDF & p-value & EDF & p-value \\
\hline Wind speed $\left(\mathrm{km} \mathrm{h}^{-1}\right)$ & & 0.002 & & $<0.001$ & & 0.002 & & $<0.001$ & & $<0.001$ \\
\hline Predictor spline & & p-value & & p-value & & p-value & & p-value & & p-value \\
\hline Tide level (m) & 1.5 & $<0.001$ & 0.0 & 0.4 & 2.2 & $<0.001$ & 2.0 & $<0.001$ & 3.4 & $<0.001$ \\
\hline Tidal velocity $\left(\mathrm{m} \mathrm{h}^{-1}\right)$ & 3.5 & $<0.001$ & 0.0 & 0.3 & 4.8 & $<0.001$ & 0.9 & 0.02 & 3.6 & $<0.001$ \\
\hline Time of day (h) & 5.6 & $<0.001$ & 7.9 & $<0.001$ & 5.4 & $<0.001$ & 3.3 & $<0.001$ & 4.2 & $<0.001$ \\
\hline Tensor product interactions & EDF & p-value & EDF & p-value & EDF & p-value & EDF & p-value & EDF & p-value \\
\hline Tide $\times$ Tidal velocity & 10.1 & $<0.001$ & 5.9 & $<0.001$ & 4.1 & 0.002 & 7.7 & $<0.001$ & 10.0 & $<0.001$ \\
\hline Tide $\times$ Wind & 2.4 & 0.006 & 6.7 & $<0.001$ & 3.2 & $<0.001$ & 4.4 & $<0.001$ & 1.2 & 0.01 \\
\hline Tide $\times$ Time of day & 13.1 & $<0.001$ & 7.8 & $<0.001$ & 14.2 & $<0.001$ & 9.5 & $<0.001$ & 14.1 & $<0.001$ \\
\hline Tidal velocity $\times$ Wind & 2.9 & $<0.001$ & 7.1 & $<0.001$ & 3.1 & 0.003 & 2.6 & 0.01 & 1.7 & 0.04 \\
\hline Tidal velocity $\times$ Time of day & 11.1 & $<0.001$ & 5.4 & $<0.001$ & 13.4 & $<0.001$ & 9.4 & $<0.001$ & 11.5 & $<0.001$ \\
\hline Wind $\times$ Time of day & 5.7 & $<0.001$ & 3.6 & 0.006 & 7.4 & $<0.001$ & 1.9 & 0.04 & 2.8 & 0.02 \\
\hline
\end{tabular}

Number of hours with calling rate at each location (n), fit of each model; $\left(\mathrm{r}^{2}\right)$, percentage of deviance explained; EDF, estimated degrees of freedom; and $p$-values are represented. In bold p-value lower than 0.05. In the formulation of GAM models, wind speed was inserted as a linear (parametric coefficients are omitted).

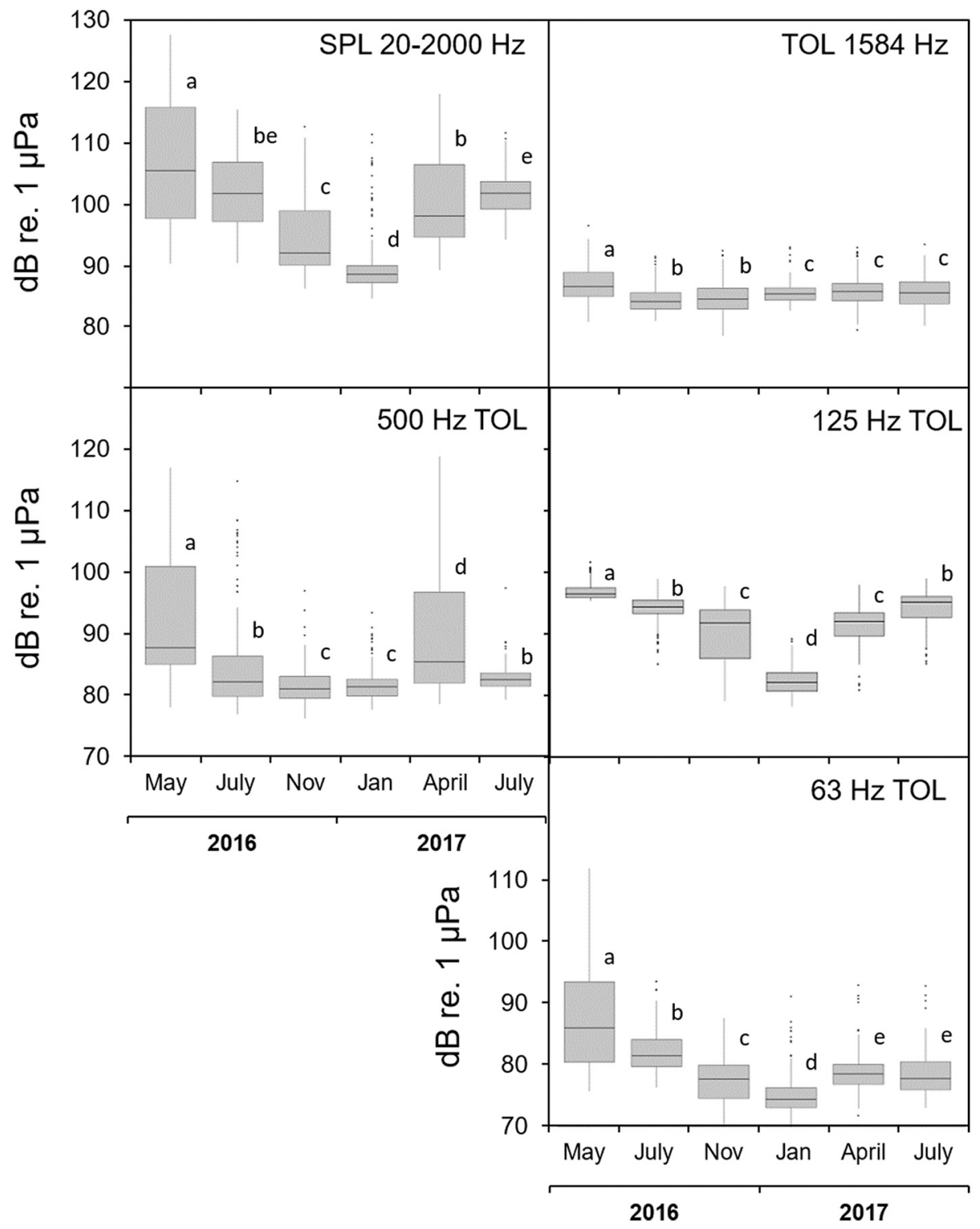

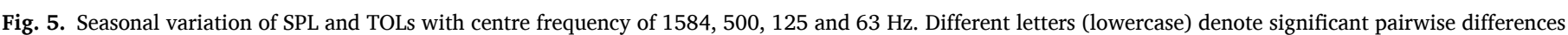
(Dunn test, $n=928 ; p<0.05$ ). 
recorded in May $2016(106.8 \pm 9.7 \mathrm{re} 1 \mu \mathrm{Pa} ; p<0.001)$, concurrent with the peak of meagre calling activity. The presence of meagre choruses could be assessed with $500 \mathrm{~Hz}$ TOL, presenting also significant differences among months (Krustal-Wallis test, $\chi_{(5)}^{2}=240.6, p<0.001$; Fig. 5). In accordance, the long-term spectrograms of May 2016 (Fig. S1) and April 2017 (Fig. 2) presented significantly higher $500 \mathrm{~Hz}$ TOL $(p<$ 0.001 ) than the other months although significant differences were also observed within these two months $(92.7 \pm 11.1$ and $90.9 \pm 12.2 \mathrm{~dB}$ re. $1 \mu \mathrm{Pa}$, respectively; $p=0.003)$. November 2016 and January 2017 exhibited the lowest values of $500 \mathrm{~Hz}$ TOL $(81.7 \pm 3.1$ and $81.6 \pm 2.7 \mathrm{~dB}$ re. $1 \mu \mathrm{Pa} ; \mathrm{p}<0.001$ ), and no significant differences were found between these colder months $(p=1)$. July 2016 showed no significant differences from July $2017(p=0.4)$. Seasonal significant differences were also found at $125 \mathrm{~Hz}$ TOL (Krustal-Wallis test, $\chi^{2}{ }_{(5)}=597.2, p<0.001$ ) and $63 \mathrm{~Hz}$ TOL (Krustal-Wallis test, $\chi_{(5)}^{2}=381.0, \mathrm{p}<0.001$; Fig. 5). May 2016 presented the highest values $(125 \mathrm{~Hz}$ TOL: $97.0 \pm 2.0 \mathrm{~dB}$ re. $1 \mu \mathrm{Pa}$, $p<0.001 ; 63 \mathrm{~Hz}$ TOL: $88.5 \pm 9.1 \mathrm{~dB}$ re. $1 \mu \mathrm{Pa} ; p<0.001$ ), while January 2017 presented the lowest values ( $125 \mathrm{~Hz}$ TOL: $82.5 \pm 3.9 \mathrm{~dB}$ re. $1 \mu \mathrm{Pa}, p$ $<0.001$; $63 \mathrm{~Hz}$ TOL: $75.3 \pm 3.6 \mathrm{~dB}$ re. $1 \mu \mathrm{Pa}$; $\mathrm{p}<0.001$ ). Furthermore, $125 \mathrm{~Hz}$ TOL presented non-significant differences between July 2016 and July 2017 ( $p=0.66$ ) or between November 2016 and April 2017 ( $p$ $=0.37) .63 \mathrm{~Hz}$ TOL presented marginally non-significant differences between November 2016 and July $2017(p=0.07)$. The 63 and $125 \mathrm{~Hz}$ centred TOLs appear to be at least partially concurrent with both fishes calling activity (see Fig. 2). $1584 \mathrm{~Hz}$ TOL presented smaller variations throughout the sampled months, but still significant differences were observed (Krustal-Wallis test, $\chi^{2}(5)=87.0, p<0.001$; Fig. 5). July and November 2016 showed significantly lower $1584 \mathrm{~Hz}$ TOL levels (84.5 \pm 2.3 and $84.7 \pm 2.5 \mathrm{~dB}$ re. $1 \mu \mathrm{Pa}$ ), while May 2016 presented the highest values $(87.2 \pm 3.2 \mathrm{~dB}$ re. $1 \mu \mathrm{Pa} ; p<0.001)$.

Spectral Probability Density plots in Fig. 6, depicting the different percentiles (1\%, 5\%, median, 95\%, 99\%) and the Root Mean Square level (RMS), illustrate the contribution of the different sound sources to the soundscape. The SPD plots of May 2016 and April 2017 exhibit a major peak observed in the higher percentiles (95\%, 99\%) and shadowed in a darker blue, which represents the presence of meagre choruses between ca. 200 and $700 \mathrm{~Hz}$. July 2016 shows also the presence of meagre and Lusitanian toadfish, but less pronounced (i.e. lower incidence of these sounds). The SPD computed from July 2017 recordings presents two pronounced peaks at about 110 and $220 \mathrm{~Hz}$, especially at the higher percentiles $(95 \%, 99 \%)$, which represents the second and third harmonics of the boatwhistles produced by the Lusitanian toadfish. This SPD denotes the absence of meagre calling activity as the peak between ca. 200 and $700 \mathrm{~Hz}$ is absent. In all SPD plots we can observe the presence of higher intensity sounds with lower incidence (lighter blue). Those represent mostly anthropogenic noise from passing boats. Peaks at ca. $1800 \mathrm{~Hz}$ up to $2000 \mathrm{~Hz}$, observable in almost all months, might be associated with tonal acoustic signatures observed in some ferryboats. Several tonal noises with low intensity (possibly anthropogenic noise from other sources) can also be observed in all the SPD plots (e.g., peak at ca. $1000 \mathrm{~Hz}$ and peaks at ca. $1600 \mathrm{~Hz}$ ). On all plots a $50 \mathrm{~Hz}$ electrical noise (and respective harmonics) from the recording setup is also noticeable.

The cumulative distribution function of SPL for each week is represented in Fig. 7. Each curve presents the proportion of time where a given sound level is reached. Lower sound levels are observed in the winter/autumn period, with sound levels under $100 \mathrm{~dB}$ re. $1 \mu \mathrm{Pa}$ ca. $80 \%$ of time. Nevertheless, November has consistently higher SPL than January (see also Fig. 5). The level exceedance for $5 \%$ of the time are $115 \mathrm{~dB}$ re. $1 \mu \mathrm{Pa}$ for November, and $107 \mathrm{~dB}$ re. $1 \mu \mathrm{Pa}$ for January. May 2016 and April 2017, show a characteristic curve with a light dome between ca. 20 and $30 \%$, possibly related with meagre choruses that dominate the soundscape at dusk. The level exceedance for $5 \%$ of the time are higher in these months with $124 \mathrm{~dB}$ re. $1 \mu \mathrm{Pa}$ in May 2016, and $117 \mathrm{~dB}$ re. $1 \mu \mathrm{Pa}$ in April 2017. The July 2017 shows a straighter curve, probably by the presence of Lusitanian toadfish chorus through day and night. The level exceedance for $5 \%$ of the time are $115 \mathrm{~dB}$ re. $1 \mu \mathrm{Pa}$ in

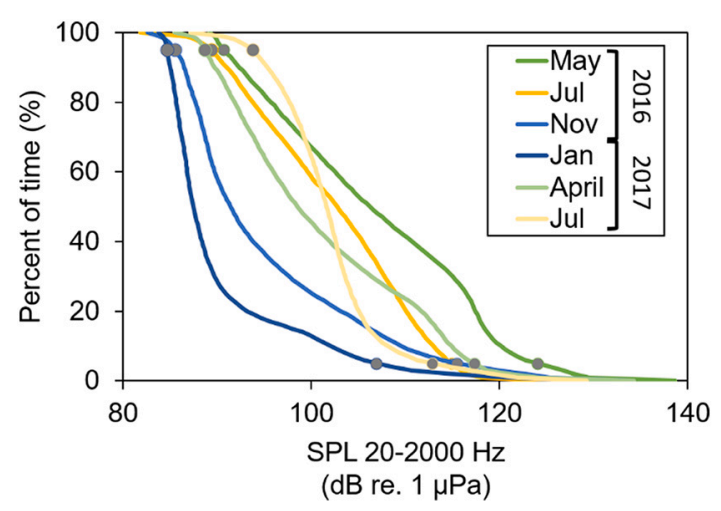

Fig. 7. Cumulative distribution function for the seasonal variation of sound pressure level (SPL). Grey circle markers indicate level exceedance for $95 \%$ and $5 \%$ of the time. SPL averaged over $60 \mathrm{~s}$ windows.

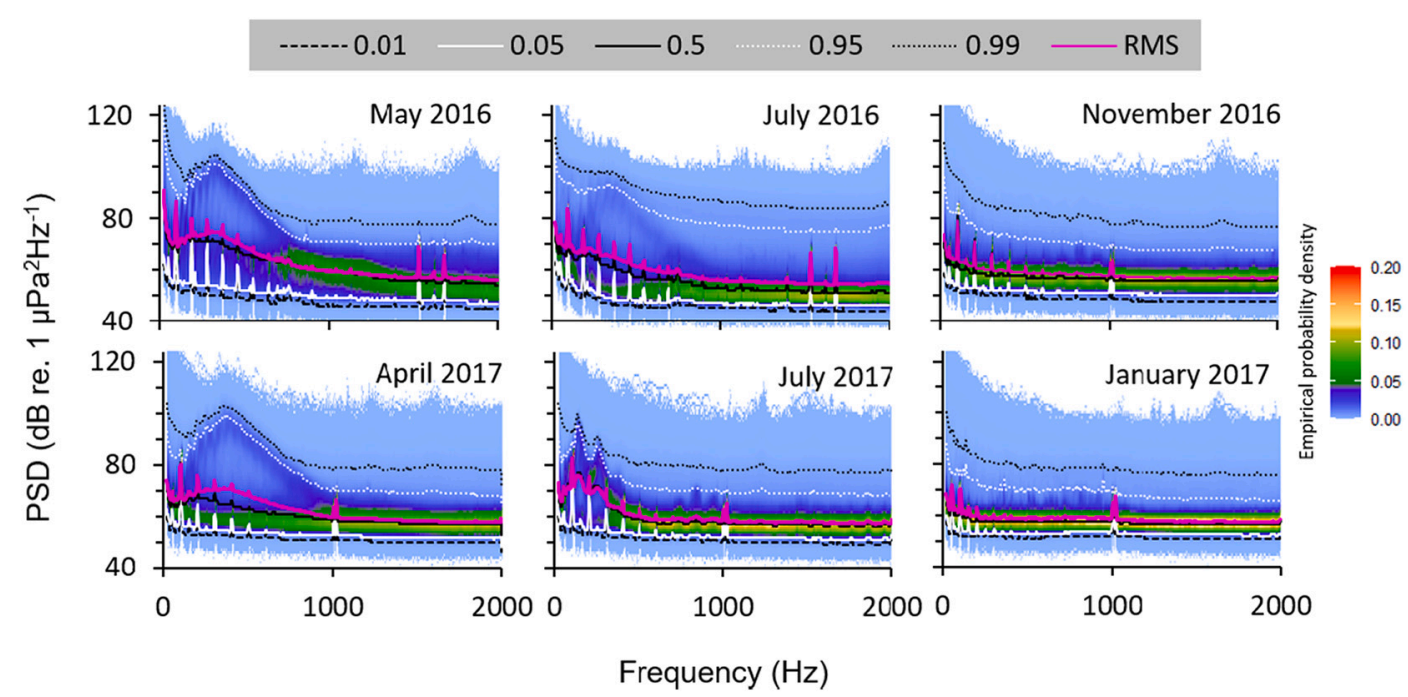

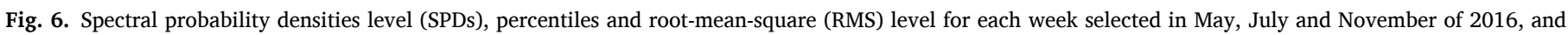
January, April and July of 2017. Note that plots are not in chronological order. 
July 2016 , and $113 \mathrm{~dB}$ re. $1 \mu \mathrm{Pa}$ in July 2017 . Note that all the curves show a tail past the $5 \%$ mark, which includes observations exceeding this mark by up to $23 \mathrm{~dB}$.

\section{Discussion}

The acoustic characteristics of marine habitats are crucial to many animals that communicate through sound or use acoustic cues to exploit their environment. This study accomplishes an important first step in characterising the soundscape of one of the largest European estuaries surrounded by a densely populated urban area. The soundscape in the shallow waters of the Tagus estuary was dominated by fish sounds with additional significant energy from anthropogenic noise and sounds produced by wind and tidal currents. Wind influenced the overall frequency range while tidal flow affected the lower frequencies of the soundscape. Boat noise was the most common anthropogenic noise and influenced all analysed bandwidths. To the best of our knowledge this is the first study characterising the soundscape in a European estuary and measuring noise levels in different times of the year.

\subsection{Soundscape sources}

\subsubsection{Biophony}

Fishes were the major contributors to the underwater soundscape. In the recorded location it is clear the presence of two of the most abundant vocal species present in the Tagus estuary (Table S1): Lusitanian toadfish and meagre. Both species are highly vocal and produce sounds especially during the spawning season (Amorim et al., 2006; Vieira et al., 2019). In the long-term spectrogram and in the SPD plots the presence of meagre was easily identified by their choruses (May and July 2016, and April 2017). Furthermore, sounds from both species were detected even in winter, indicating that several individuals of both species are residents in the estuary. Interestingly, there are other Atlantic temperate estuaries also dominated by sciaenids and toadfishes sounds (Rice et al., 2016; Monczak et al., 2017; Mueller et al., 2020).

Toadfish was only easily identified through long-term graphical methods in July 2017, when the calling rate was exceptionally high. Furthermore, fish sounds in winter were only detected by visual inspection using short-term spectrograms. Therefore, the best approach to be used when analysing biophony is to combine long-term graphical representations (e.g. long-term spectrograms and SPD) with other techniques like manual annotation or automatic recognition of sounds (e.g. Vieira et al., 2015). Note however, that automatic recognition methods enable fast detection, but usually require previous knowledge of the sound types present in a soundscape.

Sounds from other fish species were not detected. In Tagus estuary several other species are vocal or potentially vocal (Table S1), but several reasons might explain their apparent absence. Several species from the Gobiidae family can produce sounds, but they produce sounds with low intensity. In this family the communication range is usually of few centimetres (Lugli et al., 2003, Amorim et al., 2018; cf. Fig. 6 of Carriço et al. (2020b) for the estimation of the attenuation of several fish species' vocalizations), therefore it is highly improbable to record these species even if present. On the other hand, other species like the invasive Cynoscion regalis (Morais et al., 2017) might prefer other locations within the estuary. This species is highly vocal and can produce choruses like the meagre (Connaughton and Taylor, 1995). Hence, is possible that this species does not occur near our recording site but might be detected in other locations in the Tagus estuary. The same may happen in relation to other vocal species that may prefer other habitats in the estuary. This remains to be investigated.

Several potentially vocal fish species might produce sounds that could have been disregarded. Several species can, for example, produce more isolated sounds (not all vocal fish species make choruses, Amorim et al., 2015) that might thus be easily ignored if sounds are only sporadically produced. In addition, the absence of previous characterization of the sounds produced by vocal species limits the ability to detect and recognize them. There is still a major number of species that are not even confirmed as being vocal. Several studies attempted to describe unknown sounds potentially produced by fishes (Straight et al., 2014; Parsons et al., 2016; Carriço et al., 2019; Rountree et al., 2020), but were still constrained by similarities to known fish sounds. It is also important to notice the lack of a central database of sounds that could be used as reference for each species or group of species. Efforts to characterize the repertoire of vocal fish species are urgent to support soundscape analysis and ecological assessment.

\subsubsection{Anthropophony}

Anthropophony was dominated by noise from boats, both ferryboats and small boats with outboard engines usually used by fishermen. In the Tagus estuary an increase in boat traffic has occurred since the seventies (Ștefănescu et al., 2013). Cargo and passenger ships dominate the traffic reported by the Automatic Identification Systems (AIS), including a ferryboat route near our recording site (Rong et al., 2015). As reported by Vieira et al. (2020) for this location, ferryboats produce the most audible noise with higher traffic during weekdays. Boat noise has been mostly described as variable broadband sound (Hildebrand, 2009; Lester et al., 2013; Li et al., 2015), and in our case regularly presents the Lloyd effect typical from a passing-by sound source. Boat noises affect aquatic organisms' acoustic communication, behaviour and fitness (e.g. Bruintjes and Radford, 2013; Sebastianutto et al., 2011; de Jong et al., 2020). Furthermore, the observed frequency overlap with the biophony maximize its detrimental effects on the communication space of vocal species (Erbe et al., 2016; Putland et al., 2018; Alves et al., 2021). Thus, the possible higher presence of anthropogenic noise in the northern area of the estuary demands for further research using recordings on multiple sites.

Other noises were also detected, several of unknown origin. Several factories operate in the opposite margins of the recording site, including a small port for cargo ships. Furthermore, at the northern area of the estuary large cargo ships, cruisers and dredgers are common. These vessels likely have much higher source levels and can be heard at longer distances (Veirs et al., 2016). Small boats with outboard engines usually produce sound levels with $120-160 \mathrm{~dB}$ re. $1 \mu \mathrm{Pa}$ at $1 \mathrm{~m}$ depending, for example, on engine and speed (Barlett and Wilson, 2002; Hildebrand, 2009; Erbe, 2013; Lester et al., 2013). Other boats and large vessels can produce louder sounds from 130 to $190 \mathrm{~dB}$ re. $1 \mu \mathrm{Pa}$ at $1 \mathrm{~m}$ (Merchant et al., 2012; Hildebrand, 2009; McKenna et al., 2012; Wittekind, 2014; Veirs et al., 2016; Putland et al., 2018).

Our recording site is located within an Air Force base and, as such, several airplanes and helicopters pass by at low altitudes. The low frequency noise produced by aircraft can be heard underwater, but it is currently sporadic and exhibit lower intensity than the recorded boat noise. Note, however, that this area is the proposed location for a new large commercial airport (Alves and Dias, 2020) that would substantially increase air traffic noise and likely underwater noise.

\subsubsection{Geophony}

Geophony had a significant influence on the recorded Tagus estuary soundscape. Wind speed caused an increase in sound levels. This relation of wind speed with sound level is mostly a consequence of the relation between wind speed and water wave height and energy. This relation is well known (Wenz, 1962) and has been reported in other shallow waters (Haxel et al., 2013; Halliday et al., 2020). Changes in tide level and tidal current, which are related to tide ebbing and flowing, also influenced non-linearly the sound level. Tide ebbing was responsible for the highest increase in noise levels in all the frequency bandwidths. This is probably related to a combination of hydrophone self-mooring sounds, and other sounds related to the increased water currents and waves. van Geel et al. (2020) also observed a substantial tidal influence on ambient sound measurements in several locations and identified methods to exclude such sounds and highlight other sound sources. Such 
methods might be considered in measuring ambient noise on estuaries and other coastal areas.

\subsection{Sound level patterns}

\subsubsection{Daily temporal patterns}

We found time-specific differences in sound level, mostly due to rhythms in fish sound production and traffic of marine vessels. The analysis of SPL and $500 \mathrm{~Hz}$ TOL daily patterns reflected the clear diel cycles of meagre choruses (e.g. Fig. 4). Meagre peak activity occurred at dusk/beginning of night, consistent with observations in captivity (Vieira et al., 2019). Similar acoustic behaviour, i.e. restricting the calling activity to a well-defined time of day, can be found in several other species (e.g. Connaughton and Taylor, 1995; Luczkovich et al., 2008; Mann et al., 2010; Montie et al., 2017; cf. Table 1 in Vieira et al., 2021). On the other hand, for example, the splendid toadfish species in Cozumel (Caribbean Sea), just avoid singing during the day, likely due to the high presence of anthropogenic noise (Pyć et al., 2020). In our dataset, Lusitanian toadfish did not present a well-defined diel rhythm as reported by Vieira et al. (2021) but further studies should investigate the possible constrictions of the vocal activity due to the presence of boat noise. The lower 63 and $125 \mathrm{~Hz}$ TOLs during the day are consistent with the Lusitanian toadfish calling activity at this location (cf. set-up 3C in Vieira et al., 2021).

Marine traffic at this site has a marked daily pattern that can be observed in the analysis of $1584 \mathrm{~Hz}$ TOL. This higher frequency is ideal to observe these patterns because it includes boat noise while avoiding the frequency bands dominated by fish sounds. The $1584 \mathrm{~Hz}$ TOL daily pattern showed a significant decrease from ca. $11 \mathrm{pm}$ and $5 \mathrm{am}$, and a peak boating activity at ca. $8 \mathrm{am}$. This pattern is similar to the one reported by Vieira et al. (2020) using automatic recognition on recordings from the same location. The presence of daily patterns in anthropogenic noise seems common in coastal waters. Haviland-Howell et al. (2007) in coastal waters (North Carolina) and Smott et al. (2018) in May River estuary (South Carolina) also observed clear daily patterns, although more associated to recreational boaters with higher prevalence during late morning and afternoon, and higher traffic in weekends. Marley et al. (2016) in an Australian urban estuary also reported boats as the most prevalent source of anthropogenic noise with peaks around $7 \mathrm{am}, 10$ am-2 pm, and 4-7 pm.

\subsubsection{Seasonal temporal patterns}

Major seasonal differences were caused by fish calling activity. Spring (May 2016 and April 2017) was characterized by large and intense meagre choruses, causing a significant increase in the $500 \mathrm{~Hz}$ TOL. This is concurrent with the meagre vocal activity studied in captivity (Vieira et al., 2019) and is similar to what is observed is other sciaenids (e.g. Connaughton and Taylor, 1995). Lusitanian toadfish had the highest activity in July 2017. Amorim et al. (2008) reported seasonal changes of the calls produced by the Lusitanian toadfish. According to this study the calls were mostly produced in spring and summer with a peak in July. This was also concurrent with nest occupancy (Amorim et al., 2010).

No noticeable seasonal changes in anthropogenic noise were observed, although the SPL level exceedance for $5 \%$ of the time were higher in spring with $124 \mathrm{~dB}$ re. $1 \mu \mathrm{Pa}$ in May 2016, and $117 \mathrm{~dB}$ re. $1 \mu \mathrm{Pa}$ in April 2017. Only a perceptible decrease in the weekends was observed. This can be explained by the type of boats that produce the anthropogenic noise in the studied location. Most small boats are fishing boats, often also used in the catch of clams, and passenger ferryboats connecting Lisbon to Montijo, i.e. boat types with no clear seasonal activity, and that are more common on business days. In contrast, seasonal changes in anthropogenic noise are found, for example, in the touristic area of Ria Formosa, where significant changes occur due to increased vessel traffic intensity in the summer months (Soares et al., 2020).

\subsection{Soundscape and ambient noise assessment}

Here we described an estuarine soundscape and highlight the need to use several methods to visualize and quantify different sound sources. As reported by Carriço et al. (2020a) long-term spectrograms and SPD plots are important visual tools to describe marine soundscapes. Furthermore, SPL and TOLs provide a way to quantify acoustic levels and assess temporal differences.

Indicator 11.2.1 of the European MSFD highlights the importance of describing and measuring ambient noise. However, as reported by the Technical Subgroup on Underwater Noise (TSGN), this poses the obvious problem of how to deal with identifiable sources that contribute to the local soundscape and that add to the measured pressure levels. Consequently, they suggested a more operational definition of the European MSFD more in line with the term 'soundscape'.

This study highlights the necessity to use a higher frequency band than suggested by European MSFD to monitor anthropogenic noise. Specifically, the commission prescribed the use of 63 and $125 \mathrm{~Hz}$ TOLs, due to previous reports of Van der Graaf et al. (2012) on the noise produced mostly by ships. However, as our study demonstrates, these frequency bands are also occupied by fish sounds, that at least during some seasons are the major source contributing to elevated sound pressure levels. Furthermore, as reported by Merchant et al. (2014), low frequency noise from tidal flow and waves might also contaminate these low frequency bands. On the other hand, higher frequency bands might be more appropriate, at least in temperate estuaries, to indicate the presence of boat noise that also presents energy in higher frequencies up to $10 \mathrm{kHz}$ or even more. In the case of the Tagus estuary, $1548 \mathrm{~Hz}$ TOL presented good results, maybe even better that suggested before (Merchant et al., 2014; Picciulin et al., 2016). As such, the suggestion of TSGN to also measure higher frequencies appears appropriate, since these data can be obtained without considerable extra costs and may prove relevant in different shallow water habitats. Furthermore, note that in addition to underwater anthropogenic noise evaluation and management, soundscape analysis can provide data to monitor biodiversity.

\section{Conclusions}

In conclusion, in the Tagus estuary, biophony is responsible for significant seasonal variations mostly due to the presence of two vocal fish species: Lusitanian toadfish and meagre. Geophony and anthropophony substantially contributed to an increase of the soundscape sound level. However, only the combination of several methodologies allowed to interpret the shifts in recorded sound levels. Additionally, the inclusion of TOLs at frequencies higher than $1000 \mathrm{~Hz}$ may be important for MSFD noise monitoring in shallow waters. This study highlights the potential impact of boat noise. The continuous increase in anthropophony and its frequency overlap with biophony demands precautionary actions and calls for further research. Furthermore, biodiversity changes due to direct human actions and/or climate change might be observed through changes in soundscapes. This study serves as a steppingstone for soundscape and ambient noise assessment in European estuaries and may represent a baseline to monitor the Tagus estuary ecosystem.

\section{CRediT authorship contribution statement}

Conceptualization, P.J.F., M.V. and M.C.P.A; Formal analysis, M.V.; Funding acquisition, P.J.F., M.C.P.A.; Investigation, M.V.; Methodology, M.V.; Project administration, P.J.F. and M.C.P.A.; Software, M.V.; Supervision, P.J.F. and M.C.P.A.; Visualization, M.V., M.C.P.A and P.J.F.; Writing—original draft, M.V.; Writing—review \& editing, P.J.F. and M. C.P.A. 


\section{Declaration of competing interest}

The authors declare that they have no known competing financial interests or personal relationships that could have appeared to influence the work reported in this paper.

\section{Acknowledgments}

We thank the Air Force Base No. 6 of Montijo (Portugal) for allowing the field study in their military establishment and the Hydrographic Institute for providing tide level data. We are also grateful Marilia Freire and Diana Vieira for the valuable assistance during field work. This study was funded by the Science and Technology Foundation, grant SFRH/BD/115562/2016 to M.V.; strategic projects UID/MAR/04292/ 2019 to M.C.P.A. by MARE and UID/BIA/00329/2019 to P.J.F. by cE3c; and projects PTDC/BIA-BMA/30517/2017 and PTDC/BIA-BMA/ $29662 / 2017$.

\section{Appendix A. Supplementary data}

Supplementary data to this article can be found online at https://doi. org/10.1016/j.marpolbul.2021.112845.

\section{References}

Alves, D., Vieira, M., Amorim, M.C.P., Fonseca, P.J., 2021. Boat noise interferes with lusitanian toadfish acoustic communication. J. Exp. Biol. 224 (11), jeb234849.

Alves, J.A., Dias, M.P., 2020. Portugal's airport plans threaten wetlands. Science (New York, N.Y.) 369 (6510), 1440.

Amorim, M.C.P., Vasconcelos, R.O., Marques, J.F., Almada, F., 2006. Seasonal variation of sound production in the lusitanian toadfish Halobatrachus didactylus. J. Fish Biol. 69, 1892-1899.

Amorim, M.C.P., Simões, J.M., Fonseca, P.J., 2008. Acoustic communication in the lusitanian toadfish, Halobatrachus didactylus: evidence for an unusual large vocal repertoire. J. Mar. Biol. Assoc. U. K. 88 (5), 1069-1073.

Amorim, M.C.P., Simões, J.M., Fonseca, P.J., Almada, V.C., 2010. Patterns of shelter usage and social aggregation by the vocal lusitanian toadfish. Mar. Biol. 157 (3), 495-503.

Amorim, M.C.P., Vasconcelos, R.O., Fonseca, P.J., 2015. In: Fish Sounds and Mate Choice. In Sound communication in fishes. Springer, Vienna, pp. 1-33.

Amorim, M.C.P., Conti, C., Sousa-Santos, C., Novais, B., Gouveia, M.D., Vicente, J.R. Modesto, T., Gonçalves, A., Fonseca, P.J., 2016. Reproductive success in the lusitanian toadfish: influence of calling activity, male quality and experimental design. Physiol. Behav. 155, 17-24.

Amorim, M.C.P., Vasconcelos, R.O., Bolgan, M., Pedroso, S.S., Fonseca, P.J., 2018. Acoustic communication in marine shallow waters: testing the acoustic adaptive hypothesis in sand gobies. J. Exp. Biol. 221 (22).

Barlett, M.L., Wilson, G.R., 2002. Characteristics of small boat signatures. The Journal of the Acoustical Society of America 112 (5), 2221.

Bruintjes, R., Radford, A.N., 2013. Context-dependent impacts of anthropogenic noise on individual and social behaviour in a cooperatively breeding fish. Anim. Behav. 85 (6), 1343-1349.

Buscaino, G., Filiciotto, F., Gristina, M., Bellante, A., Buffa, G., Di Stefano, V., Maccarrone, V., Tranchida, G., Buscaino, C., Mazzola, S., 2011. Acoustic behaviour of the european spiny lobster Palinurus elephas. Mar. Ecol. Prog. Ser. 441, 177-184.

Cabral, H.N., Costa, M.J., Salgado, J.P., 2001. Does the tagus estuary fish community reflect environmental changes? Clim. Res. 18 (1-2), 119-126.

Carey, W.M., 2009. Lloyd's mirror-image interference effects. Acoust. Today 5 (2), 14-20.

Carriço, R., Silva, M.A., Menezes, G.M., Fonseca, P.J., Amorim, M.C.P., 2019. Characterization of the acoustic community of vocal fishes in the Azores. PeerJ 7 , e7772.

Carriço, R., Silva, M.A., Menezes, G.M., Vieira, M., Bolgan, M., Fonseca, P.J., Amorim, M. C.P., 2020b. Temporal dynamics in diversity patterns of fish sound production in the condor seamount (Azores, NE Atlantic). Deep-Sea Res. I Oceanogr. Res. Pap. 164, 103357.

Carriço, R., Silva, M. A., Vieira, M., Afonso, P., Menezes, G. M., Fonseca, P. J., \& Amorim, M. C. P. (2020). The Use of Soundscapes to Monitor Fish Communities: Meaningfu Graphical Representations Differ with Acoustic Environment. In Acoustics (Vol. 2, No. 2, pp. 382-398). Multidisciplinary Digital Publishing Institute.

Cato, D.H., Noad, M.J., McCauley, R.D., 2005. Passive Acoustics as a Key to the Study of Marine Animals. In: Medwin, H. (Ed.), Sounds in the Sea: from Ocean Acoustics to Acoustical Oceanography. Cambridge University Press, Cambridge, pp. 411-429.

Chapuis, L., Bshary, R., 2010. Signalling by the cleaner shrimp Periclimenes longicarpus. Anim. Behav. 79 (3), 645-647.

Connaughton, M.A., Taylor, M.H., 1995. Seasonal and daily cycles in sound production associated with spawning in the weakfish. Cynoscion regalis. Environmental Biology of Fishes 42 (3), 233-240.
Costa, M.J., Bruxelas, A., 1989. The structure of fish communities in the tagus estuary, Portugal, and its role as a nursery for commercial fish species. Sci. Mar. 53 (2), 561-566.

Costa, M.J., Cabral, H.N., 1999. Changes in the tagus nursery function for commercial fish species: some perspectives for management. Aquat. Ecol. 33 (3), 287-292.

de Jong, K., Forland, T.N., Amorim, M.C.P., Rieucau, G., Slabbekoorn, H., Sivle, L.D., 2020. Predicting the effects of anthropogenic noise on fish reproduction. Rev. Fish Biol. Fish. 1-24.

Erbe, C., 2013. Underwater noise of small personal watercraft (jet skis). The Journal of the Acoustical Society of America 133 (4), EL326-EL330.

Erbe, C., Reichmuth, C., Cunningham, K., Lucke, K., Dooling, R., 2016. Communication masking in marine mammals: a review and research strategy. Mar. Pollut. Bull. 103 (1-2), 15-38.

European Commission, (2008). Directive 2008/56/EC of the European Parliament and of the Council of 17 June 2008 establishing a framework for Community actions in the field of marine environmental policy (Marine Strategy Framework Directive MSFD), Official Journal of the European Communities, L164/19.

Farina, A., 2019. Ecoacoustics: a quantitative approach to investigate the ecological role of environmental sounds. Mathematics 7 (1), 21.

Farina, A., Gage, S.H. (Eds.), 2017. Ecoacoustics: The ecological role of sounds. John Wiley \& Sons.

Halliday, W.D., Scharffenberg, K., Whalen, D., MacPhee, S.A., Loseto, L.L., Insley, S.J., 2020. The summer soundscape of a shallow-water estuary used by beluga whales in the western Canadian Arctic. Arctic Science 1-23.

Hastie, T., Tibshirani, R., 1990. Generalized Additive Models. Chapman and Hall/CRC, London.

Haviland-Howell, G., Frankel, A.S., Powell, C.M., Bocconcelli, A., Herman, R.L., Sayigh, L.S., 2007. Recreational boating traffic: a chronic source of anthropogenic noise in the Wilmington, North Carolina intracoastal waterway. The Journal of the Acoustical Society of America 122 (1), 151-160.

Haxel, J.H., Dziak, R.P., Matsumoto, H., 2013. Observations of shallow water marine ambient sound: the low frequency underwater soundscape of the Central Oregon coast. The Journal of the Acoustical Society of America 133 (5), 2586-2596.

Hildebrand, J.A., 2009. Anthropogenic and natural sources of ambient noise in the ocean. Mar. Ecol. Prog. Ser. 395, 5-20.

Imo, 2001. Guidelines for the Onboard Operational Use of Shipborne Automatic Identification System (AIS), a.917 (22). International Maritime Organization (IMO).

Kaatz, I.M., 2002. Multiple sound producing mechanisms in teleost fishes and hypotheses regarding their behavioural significance. Bioacoustics 12, 230-233.

Krause, B., Farina, A., 2016. Using ecoacoustic methods to survey the impacts of climate change on biodiversity. Biol. Conserv. 195, 245-254.

Lagardère, J.P., Mariani, A., 2006. Spawning sounds in meagre Argyrosomus regius recorded in the gironde estuary. France. Journal of Fish Biology 69 (6), 1697-1708.

Lester, L.A., Avery, H.W., Harrison, A.S., Standora, E.A., 2013. Recreational boats and turtles: behavioral mismatches result in high rates of injury. PloS one 8 (12), e82370.

Li, S., Wu, H., Xu, Y., Peng, C., Fang, L., Lin, M., Xing, P., Zhang, P., 2015. Mid-to highfrequency noise from high-speed boats and its potential impacts on humpback dolphins. The Journal of the Acoustical Society of America 138 (2), 942-952.

Lillis, A., Eggleston, D.B., Bohnenstiehl, D.R., 2014. Estuarine soundscapes: distinct acoustic characteristics of oyster reefs compared to soft-bottom habitats. Mar. Ecol. Prog. Ser. 505, 1-17.

Luczkovich, J.J., Pullinger, R.C., Johnson, S.E., Sprague, M.W., 2008. Identifying sciaenid critical spawning habitats by the use of passive acoustics. Trans. Am. Fish. Soc. 137 (2), 576-605.

Lugli, M., Yan, H.Y., Fine, M.L., 2003. Acoustic communication in two freshwater gobies: the relationship between ambient noise, hearing thresholds and sound spectrum. J. Comp. Physiol. A. 189 (4), 309-320.

Mann, D., Locascio, J., Schärer, M., Nemeth, M., Appeldoorn, R., 2010. Sound production by red hind Epinephelus guttatus in spatially segregated spawning aggregations. Aquat. Biol. 10 (2), 149-154.

Mann, D.A., Lobel, P.S., 1997. Propagation of damselfish (Pomacentridae) courtship sounds. The Journal of the Acoustical Society of America 101 (6), 3783-3791.

Marley, S.A., Erbe, C., Salgado-Kent, C.P., 2016. Underwater sound in an urban estuarine river: sound sources, soundscape contribution, and temporal variability. Acoustics Australia 44 (1), 171-186.

Marques, T.A., Thomas, L., Martin, S.W., Mellinger, D.K., Ward, J.A., Moretti, D.J., Harris, D., Tyack, P.L., 2013. Estimating animal population density using passive acoustics. Biol. Rev. 88 (2), 287-309.

McKenna, M.F., Ross, D., Wiggins, S.M., Hildebrand, J.A., 2012. Underwater radiated noise from modern commercial ships. The Journal of the Acoustical Society of America 131 (1), 92-103.

McWilliam, J., Hawkins, A., 2013. A comparison of inshore marine soundscapes. J. Exp. Mar. Biol. Ecol. 446, 166-176. https://doi.org/10.1016/j.jembe.2013.05.012.

Merchant, N.D., Blondel, P., Dakin, D.T., Dorocicz, J., 2012. Averaging underwater noise levels for environmental assessment of shipping. The Journal of the Acoustical Society of America 132 (4), EL343-EL349.

Merchant, N.D., Pirotta, E., Barton, T.R., Thompson, P.M., 2014. Monitoring ship noise to assess the impact of coastal developments on marine mammals. Mar. Pollut. Bull. 78 (1-2), 85-95.

Merchant, N.D., Fristrup, K.M., Johnson, M.P., Tyack, P.L., Witt, M.J., Blondel, P., Parks, S.E., 2015. Measuring acoustic habitats. Methods Ecol. Evol. 6 (3), 257-265.

Monczak, A., Berry, A., Kehrer, C., Montie, E.W., 2017. Long-term acoustic monitoring of fish calling provides baseline estimates of reproductive timelines in the May River estuary, southeastern USA. Mar. Ecol. Prog. Ser. 581, 1-19. 
Monczak, A., Ji, Y., Soueidan, J., Montie, E.W., 2019. Automatic detection, classification, and quantification of sciaenid fish calls in an estuarine soundscape in the Southeast United States. PloS one 14 (1), e0209914.

Montgomery, J.C., Radford, C.A., 2017. Marine bioacoustics. Curr. Biol. 27 (11), R502-R507.

Montie, E.W., Hoover, M., Kehrer, C., Yost, J., Brenkert, K., O’Donnell, T., Denson, M.R. 2017. Acoustic monitoring indicates a correlation between calling and spawning in captive spotted seatrout (Cynoscion nebulosus). PeerJ 5, e2944.

Morais, P., Cerveira, I., Teodósio, M.A., 2017. An update on the invasion of weakfish Cynoscion regalis (Bloch \& Schneider, 1801)(Actinopterygii: Sciaenidae) into Europe. Diversity 9 (4), 47.

Mueller, C., Monczak, A., Soueidan, J., McKinney, B., Smott, S., Mills, T., Ji, Y., Montie, E.W., 2020. Sound characterization and fine-scale spatial mapping of an estuarine soundscape in the southeastern USA. Mar. Ecol. Prog. Ser. 645, 1-23.

Nabi, G., McLaughlin, R.W., Hao, Y., Wang, K., Zeng, X., Khan, S., Wang, D., 2018. The possible effects of anthropogenic acoustic pollution on marine mammals' reproduction: an emerging threat to animal extinction. Environ. Sci. Pollut. Res. 25 (20), 19338-19345.

Normandeau Associates, Inc, 2012. Effects of noise on fish, fisheries, and invertebrates in the u.s.Atlantic and Arctic from energy industry sound-generating activities. In: A literature synthesis for the U.S. Dept. of the Interior, Bureau of Ocean Energy Management.

Obrist, M.K., Pavan, G., Sueur, J., Riede, K., Llusia, D., Márquez, R., 2010. Bioacoustics approaches in biodiversity inventories. Abc Taxa 8, 68-99.

Parsons, M.J., Salgado-Kent, C.P., Marley, S.A., Gavrilov, A.N., McCauley, R.D., 2016. Characterizing diversity and variation in fish choruses in Darwin harbour. ICES J. Mar. Sci. 73 (8), 2058-2074.

Pavan, G., 2017. Fundamentals of soundscape conservation. In: Ecoacoustics: The ecological role of sounds. John Wiley \& Sons, pp. 235-258.

Picciulin, M., Sebastianutto, L., Fortuna, C.M., Mackelworth, P., Holcer, D., Gospić, N.R., 2016. In: Are the 1/3-Octave Band 63-and 125-Hz Noise Levels Predictive of Vesse Activity? The Case in the Cres-Lošinj Archipelago (Northern Adriatic Sea, Croatia). In The effects of noise on aquatic life II. Springer, New York, NY, pp. 821-828.

Pijanowski, B.C., Farina, A., Gage, S.H., Dumyahn, S.L., Krause, B.L., 2011. What is soundscape ecology? An introduction and overview of an emerging new science. Landsc. Ecol. 26 (9), 1213-1232.

Popper, A.N., Hastings, M.C., 2009. The effects of anthropogenic sources of sound on fishes. J. Fish Biol. 75 (3), 455-489.

Popper, A.N., Hawkins, A.D., 2009. An overview of fish bioacoustics and the impacts of anthropogenic sounds on fishes. J. Fish Biol. 94, 692-713. https://doi.org/10.1111/ jfb.13948.

Putland, R.L., Constantine, R., Radford, C.A., 2017. Exploring spatial and temporal trends in the soundscape of an ecologically significant embayment. Sci. Rep. 7 (1), $1-12$.

Putland, R.L., Merchant, N.D., Farcas, A., Radford, C.A., 2018. Vessel noise cuts down communication space for vocalizing fish and marine mammals. Glob. Chang. Biol. 24 (4), 1708-1721.

Pyć, C. D., Vallarta, J., Rice, A. N., Zeddies, D. G., Maxner, E. E., \& Denes, S. L. 2020 Vocal behavior of the endangered splendid toadfish and potential masking by anthropogenic noise. Conservation Science and Practice, e352.

R Core Team, 2018. R: a Language and Environment for Statistical Computing. R Foundation for Statistical Computing, Vienna, Austria. URL: https://www.R-project. org/.

Radford, C.A., Stanley, J.A., Tindle, C.T., Montgomery, J.C., Jeffs, A.G., 2010. Localised coastal habitats have distinct underwater sound signatures. Mar. Ecol. Prog. Ser. 401, 21-29.

Remage-Healey, L., Douglas, R., Nowacek, P., Bass, A.H., 2006. Dolphin foraging sounds suppress calling and elevate stress hormone levels in a prey species, the Gulf toadfish. J. Exp. Biol. 209, 4444-4451.

Rice, A.N., Morano, J.L., Hodge, K.B., Muirhead, C.A., 2016. Spatial and temporal patterns of toadfish and black drum chorusing activity in the South Atlantic bight. Environ. Biol. Fish 99 (10), 705-716.

Rodrigues, M., Cravo, A., Freire, P., Rosa, A., Santos, D., 2020. Temporal assessment of the water quality along an urban estuary (Tagus estuary, Portugal). Mar. Chem. 223, 103824.

Romagosa, M., Cascão, I., Merchant, N.D., Lammers, M.O., Giacomello, E., Marques, T. A., Silva, M.A., 2017. Underwater ambient noise in a baleen whale migratory habitat off the Azores. Front. Mar. Sci. 4, 109.

Rong, H., Teixeira, A.P., Guedes Soares, C., 2015. Simulation and Analysis of Maritime Traffic in the Tagus River Estuary Using AIS Data. Taylor \& Francis Group, London, pp. 185-193.
Rountree, R.A., Juanes, F., Bolgan, M., 2020. Temperate freshwater soundscapes: a cacophony of undescribed biological sounds now threatened by anthropogenic noise. Plos one 15 (3), e0221842.

Santos, F. D., Forbes, K., \& Moita, R. (Eds.). (2002). Climate change in Portugal: scenarios, impacts and adaptation measures: SIAM Project. Gradiva.

Sebastianutto, L., Picciulin, M., Costantini, M., Ferrero, E.A., 2011. How boat noise affects an ecologically crucial behaviour: the case of territoriality in Gobius cruentatus (Gobiidae). Environ. Biol. Fish 92 (2), 207-215.

Smott, S., Monczak, A., Miller, M.E., Montie, E.W., 2018. Boat noise in an estuarine soundscape-A potential risk on the acoustic communication and reproduction of soniferous fish in the May River, South Carolina. Mar. Pollut. Bull. 133, 246-260.

Soares, C., Pacheco, A., Zabel, F., Gonzalez-Goberna, E., Sequeira, C., 2020. Baseline assessment of underwater noise in the ria Formosa. Mar. Pollut. Bull. 150, 110731.

Staaterman, E., Paris, C.B., DeFerrari, H.A., Mann, D.A., Rice, A.N., D’Alessandro, E.K., 2014. Celestial patterns in marine soundscapes. Mar. Ecol. Prog. Ser. 508, 17-32.

Ștefănescu, P., de Sousa Tavares, D. P., Mocan, M., \& Ștefănescu, W. (2013). Public Transportation on River Tagus. In Proceedings of the International Conference on Knowledge Discovery and Information Retrieval and the International Conference on Knowledge Management and Information Sharing - Volume 1: KMIS, 502-507.

Straight, C.A., Freeman, B.J., Freeman, M.C., 2014. Passive acoustic monitoring to detect spawning in large-bodied catostomids. Trans. Am. Fish. Soc. 143 (3), 595-605.

Sueur, J., Farina, A., 2015. Ecoacoustics: the ecological investigation and interpretation of environmental sound. Biosemiotics 8 (3), 493-502.

Sueur, J., Pavoine, S., Hamerlynck, O., Duvail, S., 2008. Rapid acoustic survey for biodiversity appraisal. PloS one 3 (12), e4065.

Tavares, A.O., dos Santos, P.P., Freire, P., Fortunato, A.B., Rilo, A., Sá, L., 2015. Flooding hazard in the tagus estuarine area: the challenge of scale in vulnerability assessments. Environ. Sci. Pol. 51, 238-255.

Thiel, R., Cabral, H., Costa, M.J., 2003. Composition, temporal changes and ecologica guild classification of the ichthyofaunas of large european estuaries-a comparison between the tagus (Portugal) and the elbe (Germany). J. Appl. Ichthyol. 19 (5), $330-342$.

Towsey, M., Parsons, S., Sueur, J., 2014. Ecology and acoustics at a large scale. Ecological Informatics: an international journal on ecoinformatics and computational ecology 21, 1-3.

Van der Graaf, A.J., Ainslie, M.A., André, M., Brensing, K., Dalen, J., Dekeling, R.P.A., Robinson, S., Tasker, M.L., Thomsen, F., Werner, S., 2012. European Marine Strategy Framework Directive-Good Environmental Status (msfd ges): Report of the Technical Subgroup on Underwater Noise and Other Forms of Energy. TSG Noise \& Milieu Ltd, Brussels.

van Geel, N.C., Merchant, N.D., Culloch, R.M., Edwards, E.W., Davies, I.M., O'Hara Murray, R.B., Brookes, K.L., 2020. Exclusion of tidal influence on ambient sound measurements. The Journal of the Acoustical Society of America 148 (2), 701-712.

Veirs, S., Veirs, V., Wood, J.D., 2016. Ship noise extends to frequencies used for echolocation by endangered killer whales. PeerJ 4, e1657.

Vermeij, M.J.A., Marhaver, K.L., Huijbers, C.M., Nagelkerken, I., Simpson, S.D., 2010. Coral larvae move toward reef sounds. PLoS ONE 5 (5), e10660. https://doi.org/ 10.1371/journal.pone.0010660.

Vieira, M., Fonseca, P.J., Amorim, M.C.P., Teixeira, C.J., 2015. Call recognition and individual identification of fish vocalizations based on automatic speech recognition: an example with the lusitanian toadfish. The Journal of the Acoustical Society of America 138 (6), 3941-3950.

Vieira, M., Pereira, B.P., Pousão-Ferreira, P., Fonseca, P.J., Amorim, M., 2019. Seasonal variation of captive meagre acoustic signalling: a manual and automatic recognition approach. Fishes 4 (2), 28.

Vieira, M., Amorim, M.C.P., Sundelöf, A., Prista, N., Fonseca, P.J., 2020. Underwater noise recognition of marine vessels passages: two case studies using hidden markov models. ICES J. Mar. Sci. 77 (6), 2157-2170.

Vieira, M., Amorim, M.C.P., Fonseca, P.J., 2021. Vocal rhythms in nesting lusitanian toadfish, Halobatrachus didactylus. Ecological Informatics 63, 101281.

Wenz, G.M., 1962. Acoustic ambient noise in the ocean: spectra and sources. The Journal of the Acoustical Society of America 34 (12), 1936-1956.

Wittekind, D.K., 2014. A simple model for the underwater noise source level of ships. Journal of Ship production and design 30 (1), 7-14.

Wood, S., 2006. Low-rank scale-invariant tensor product smooths for generalized additive mixed models. Biometrics 62, 1025-1036.

Wood, S., 2017. Generalized Additive Models: an Introduction with R, 2nd ed. Chapman and Hall/CRC, London.

Wood, S.N., 2001. Mgcv: GAMs and generalized ridge regression for R. R news 1 (2), 20-25. 